\title{
Determinados contornos jurídicos, assistenciais e econômicos de organizações cristãs
}

\author{
Juridical, assistance and economic contours \\ of Christian organizations
}

(1) André Ricardo de Souza*

\begin{abstract}
Resumo: O cristianismo no Brasil é composto por vertentes e instituições atuantes em diversas áreas, abrangendo o tradicional trabalho de assistência social e o controverso empreendedorismo econômico, sobremaneira midiático. Cumpre lembrar que para o exercício dessas atividades é necessário o amparo legal e a decorrente permissão do estado. Neste artigo, são tratados determinados aspectos da legislação brasileira quanto a organizações cristãs, sobremaneira suas atividades assistenciais e econômicas. Produzido com base em pesquisa bibliográfica, análise de documentos e consulta sistematizada a fontes jornalísticas relevantes, o texto dá atenção à questão da isenção fiscal e também do apoio governamental, ainda que indireto, a organizações cristãs e seus líderes para a realização de suas atividades.
\end{abstract}

Palavras-chave: Estado e religião. Organizações cristãs. Religião e assistência social. Legislação. Religião e atividade econômica.

Abstract: The Christianity in Brazil consists of branches and institutions with activities in various fields, including the traditional social assistance work and the controversial economic entrepreneurship, mainly in the area of mass media. For these activities a permission from the state and the deriving legal support are necessary. Some features of the Brazilian legislation about the Christian organizations are tackled in this article, mainly those of assistance work and economic activities. The research is based on bibliographic and documentary analysis as well as on systematic consultation of journalistic resources. The article focuses on the question of tax exemption and the even indirect support of the state for the activities of the Christian organizations and their leaders.

Keywords: State and religion. Christian organizations. Religion and social assistance. Legislation. Religion and economic activities.

Resumen: El cristianismo en Brasil es compuesto por vertientes e instituciones actuantes en diversos campos, abarcando el tradicional trabajo de asistencia social y el controvertido emprendedorismo económico, sobremanera el mediático. Es

\footnotetext{
* Doutor em Sociologia pela Universidade de São Paulo (USP, São Paulo, SP, Brasil) e professor adjunto do Departamento e do PPG em Sociologia da Universidade Federal de São Carlos em São Carlos, SP, Brasil<anrisouza@uol.com.br>.
}

Civitas, Porto Alegre, v. 18, n. 1, p. 237-255, jan.-abr. 2018

Exceto onde especificado diferentemente, a matéria publicada neste periódico

é licenciada sob forma de uma licença

Creative Commons Attribution-NonCommercial-NoDerivatives 4.0 International License 
importante decir que para el ejercicio de esas actividades es necesario el amparo legal y el consecuente permiso del estado. En este artículo, se tratan determinados aspectos de la legislación brasileña sobre organizaciones cristianas, sobremanera relativas a sus actividades asistenciales y económicas. Elaborado sobre la base de investigaciones bibliográficas, análisis de documentos y consulta sistematizada a fuentes periodísticas relevantes, el texto se centra en la cuestión de la exención fiscal y también del apoyo estatal, aunque indirecto, a organizaciones cristianas y sus líderes para la realización de sus actividades.

Palabras clave: Estado y religión. Organizaciones cristianas. Religión y asistencia social. Legislación. Religión y actividad económica.

\section{Introdução}

Este artigo decorre de uma pesquisa finalizada sobre as maiores vertentes cristãs no Brasil em termos de suas principais práticas econômicas e assistenciais, com respectivas implicações políticas. ${ }^{1}$ Surgiu a partir da busca de compreensão do processo de crescimento das atividades econômicas e dos recursos financeiros movimentados por grupos cristãos. ${ }^{2}$ Os investimentos se dão em diversos ramos de atividade econômica, principalmente nos meios de comunicação social, com destaque para as redes de televisão e rádio. O desenvolvimento do aparato comunicativo contribui para o crescimento de igrejas evangélicas e também de comunidades católicas originárias do movimento da Renovação Carismática.

De outro lado, no espectro cristão, é bastante tradicional, além de abrangente, a sua presença no campo da assistência social. Ela se dá através de hospitais, escolas, abrigos de idosos e crianças, centros comunitários e redes de voluntários. Parcerias e convênios estabelecidos entre as organizações religiosas e governos, não apenas mantêm, mas também reforçam o trabalho assistencial feito por elas, por vezes, com feições proselitistas. ${ }^{3}$

Expondo dados obtidos mediante consulta sistematizada à bibliografia sociológica pertinente e também a alguns documentos institucionais e relevantes fontes jornalísticas, o texto discute, numa perspectiva menos

\footnotetext{
${ }^{1}$ Esta investigação, voltada sobremaneira para a relação entre religião cristã e economia, contou com auxílio da Fundação de Amparo à Pesquisa do Estado de São Paulo (Fapesp).

${ }^{2}$ Este conjunto abrange igrejas e demais entidades evangélicas, católicas e também espíritas kardecistas, dada a materialização nestas do princípio da caridade através de suas obras assistenciais.

${ }^{3}$ Há uma ampla gama de instituições privadas sem fins lucrativos, entre elas as religiosas, que realizam atividades assistenciais recebendo recursos públicos e transmitindo através delas suas mensagens doutrinárias.
} 
empírica e mais teórica, determinados aspectos da permissão legal e mesmo do apoio institucional que as organizações cristãs recebem do estado para realizar suas atividades assistenciais e econômicas. Cada vez mais, tais práticas se combinam com aquelas estritamente religiosas que abrangem: cultos, pregações e aconselhamentos. ${ }^{4}$ Bem mais que as assistenciais, são as atividades econômicas as que já envolvem controvérsias, além de ações judiciais (Lobato, 2005, p. 181-206; Souza, 2011, p. 19-24).

Movidos por valores doutrinários e em nome dos interesses de seus grupos, atores religiosos também vêm, cada vez mais, assumindo atuação político-partidária, com destaque para os evangélicos, unidos pelo discurso em prol da liberdade de culto. Tal participação política também acaba por propiciar vantagens objetivas no campo econômico, algo que abrange, por exemplo, negociações em prol do funcionamento de emissoras de rádio e televisão, construção de templos e realização de eventos massivos. Nesse cenário, se discute o modo com que determinados líderes e grupos religiosos se engajam em atividades economicamente empreendedoras, gerando consideráveis excedentes e gozando de alguns privilégios em relação aos concorrentes nos segmentos em que atuam (Pierucci, 1996; Mariano, 2003a; Oro, Corten e Donzon, 2003; Souza, 2011).

O interesse econômico-corporativo de lideranças religiosas é um dos vetores de inserção delas ou de seus representantes na política partidária. Nesse sentido, sobressai a Igreja Universal do Reino de Deus (Iurd) e ocupantes de cargos públicos filiados à legenda bastante ligada a ela: o Partido Republicando Brasileiro (PRB). Atividades midiáticas e também assistenciais servem algumas vezes como espécie de trampolim para a construção de carreiras políticas. Parlamentares ganham visibilidade através da música gospel e do envolvimento com projetos sociais vinculados a suas igrejas, sendo o maior exemplo o bispo licenciado da Iurd e atual prefeito do Rio de Janeiro: Marcelo Crivella.

Neste artigo são discutidos aspectos da legislação brasileira em relação às organizações religiosas, sobremaneira quanto aos traços assistenciais e econômicos delas. Circunstâncias políticas e determinadas implicações do processo histórico de mudança de algumas das principais leis e normas em relação às instituições cristãs foram levados em conta, buscando problematizar o amparo legal e institucional que elas contam para a realização de suas

\footnotetext{
${ }^{4}$ Conforme destacou Paula Montero (2012, p. 173): "No processo de ampliação das competências do religioso as próprias organizações se modificaram de tal modo que, em alguns casos, tornase difícil distinguir se estamos diante de um arranjo religioso, ou de um arranjo empresarial, acadêmico ou propriamente político"
} 
atividades. É dada atenção também a algumas controvérsias ligadas à movimentação financeira de determinadas igrejas.

\section{Variação da relação estado-religião no Brasil}

O Brasil se encaixa no grupo dos países caracterizados por um regime de "separação igreja-estado", que confere à Igreja Católica, ao menos em tese, menor reconhecimento oficial, dada a sustentação legal da separação do estado, que deve tratar com isonomia todas as organizações religiosas, sem qualquer distinção (Oro e Ureta, 2007). Tal separação formal aconteceu a partir do Decreto 119-A, de 7 de janeiro de 1890, quase dois meses após a instauração da República. Aquele documento reconhecia a "todas as igrejas e confissões religiosas" a "personalidade jurídica para adquirirem os bens e os administrarem", mas "sob os limites postos pelas leis concernentes à propriedade de mão-morta", ou seja, conjunto de bens incorporados à igreja (artigo $5^{\circ}$ ). A primeira constituição republicana, promulgada em 1891, basicamente oficializou: o casamento civil, a secularização dos cemitérios, o fim da intervenção estatal nas contas de instituições religiosas e o estabelecimento do ensino laico nas escolas. Asseverou também, conforme o parágrafo $3^{\circ}$ do artigo 72 , que: “Todos os indivíduos e confissões religiosas podem exercer publicamente o seu culto, associando-se para esse fim e adquirindo bens, observadas as disposições do direito comum" (cf. Scampini, 1978; Romano, 1979; Beozzo, 2000; Giumbelli, 2002, p. 238-261; 2008, p. 82).

Após esse rompimento, igreja e estado só voltariam a se aproximar efetivamente durante o governo de Getúlio Vargas (1930-1945). A amizade entre ele e o arcebispo do Rio de Janeiro e grande liderança católica de então, dom Sebastião Leme, teve bastante peso nesse processo de reconciliação, cujo marco foi a Constituição de 1934, em que o casamento católico voltou a ter validade civil e o ensino religioso se tornou não mais obrigatório, como antes no Império, mas apenas legalmente permitido. Porém o fato principal do texto constitucional foi ter mitigado a separação jurídica de 1891 ao prever a "colaboração recíproca" entre estado e religião, na prática: Igreja Católica (Della Cava, 1975; Giumbelli, 2002; 2008, p. 82-92; Oro, 2006, p. 85).

Já a Constituição de 1946 reafirmaria em seu artigo 31, incisos II e III, o princípio da separação entre estado e igreja e também da colaboração do poder público brasileiro com a instituição romana em prol do chamado bem comum. Além disso, viria assegurar a imunidade tributária às instituições religiosas, algo que já vinha sendo aplicado através de algumas leis locais 
específicas, ${ }^{5}$ assim como o livre recebimento de bens e a proteção quanto ao desembaraço deles (Giumbelli, 2008, p. 92). A Carta Magna posterior, de 1967, em seu artigo 9o, inciso II, reiterou essa separação institucional. Tal artigo restringia a "colaboração recíproca" presente nas Constituições de 1934 e 1946, afirmando que ela só deveria ocorrer se fosse voltada ao interesse público, especificamente nos setores: educacional, assistencial e hospitalar.

Essa colaboração recíproca entre estado e organizações religiosas, em termos de educação, saúde e assistência social, acabou sendo mantida na Constituição de 1988, através de seu artigo 19o, inciso I. Tal artigo permite subsídios públicos a instituições religiosas para a realização de atividades nessas áreas. Isso se mantém como parte do marco legal brasileiro em face das religiões. Aquela carta magna também manteve a invocação a Deus em seu preâmbulo e o texto introdutório que enuncia propósitos, repetindo os documentos constitucionais anteriores, com exceção aos de 1891 e 1937 (Pinheiro, 2008; Giumbelli, 2008; Ranquetat Jr., 2013).

Em termos de legislação, mudanças nacionalmente significativas quanto à religião voltariam a ocorrer no Brasil somente em 2003, durante o primeiro ano de governo de Luiz Inácio Lula da Silva. Trata-se do processo de regulamentação do novo Código Civil, contemplado na Lei 10.406 , de 2002. A versão anterior, elaborada em 1916 e vigente desde o ano seguinte, era antecedida e respaldada pela Lei 173, de 1893, prevendo a não restrição por parte do estado em relação à gestão e à vida econômica das associações religiosas; liberdade de tais associações para ter personalidade jurídica e registro civil sem autorização prévia; e submissão delas ao mesmo regime legal das sociedades sem fins lucrativos. Seu artigo 16, incisos I e II, prescrevia que "as sociedades civis, religiosas, pias, morais, científicas ou literárias, as associações de utilidade pública e as fundações" são "pessoas jurídicas de direito privado" (Giumbelli, 2002, p. 273-274; 2008, p. 83). A proposta de mudança no Código Civil, de 2003, continha atribuições ao estado de regulação das associações em geral (inclusive as religiosas), reforçava os direitos de seus membros em contraponto a seus dirigentes, reiterava a proibição de lucro, exigindo a manutenção e a disponibilidade de registros contábeis, além da declaração de renda. Em suma, as associações religiosas passariam a receber o mesmo tipo de fiscalização exercido pelo poder público em relação às organizações laicas sem fins lucrativos e

${ }^{5}$ Tal imunidade incidia basicamente sobre o imposto predial de templos e demais imóveis. Esse benefício era concedido, no Rio de Janeiro, por exemplo, com base em leis ainda do Império, ratificadas em decretos municipais (Giumbelli, 2002, p. 279). 
teriam que prestar contas efetivamente a todos os seus membros-contribuintes.

Argumentando haver uma perseguição laicista, tal como feito em relação à mobilização para a eleição da Assembleia Constituinte em 1986, os parlamentares evangélicos se articularam com seus colegas católicos, contando com o respaldo da Conferência Nacional dos Bispos do Brasil (CNBB) para a alteração no projeto de lei. ${ }^{6}$ A organização católica se empenhou fortemente para esse fim. ${ }^{7}$ Aliados, os parlamentares cristãos tiveram êxito, fazendo com que o então presidente Lula sancionasse a Lei 10.825 , tal como havia sido aprovada no Congresso Nacional. Obtiveram a modificação de dois pontos estratégicos da legislação que instituiu o novo código. Seu artigo 10 afirma: "Esta lei define as organizações religiosas e os partidos políticos como pessoas jurídicas de direito privado, desobrigando-as de alterar seus estatutos no prazo previsto pelo artigo 2.031 da Lei 10.046 , de 10 de janeiro de 2002 - Código Civil". No artigo 44 do Código, passou a constar o seguinte parágrafo: "São livres a criação, a organização, a estruturação interna e o funcionamento das organizações religiosas, sendo vedado ao poder público negar-lhes reconhecimento ou registro dos constitutivos e necessários ao seu funcionamento".

Com a modificação surgiu no cenário jurídico brasileiro a figura das organizações religiosas, que são desatreladas da regulação prevista às associações em geral. Basicamente, tais organizações permaneceram isentas de registro de estatuto social, aprovado em assembleia geral interna, e a consequente prestação de contas a todos os seus membros-contribuintes sobre as atividades realizadas e os recursos movimentados. A sanção presidencial à modificação específica do Novo Código Civil quanto às organizações religiosas acabou sendo ressaltada por Lula, já em campanha subliminar para sua reeleição em 2006. O então presidente ressaltou que ele havia sido maciçamente rejeitado pelos evangélicos nas três primeiras eleições que disputara - 1989, 1994 e $1998^{8}$ - designando tal sansão como "importante ato em favor da liberdade religiosa" (Mariano, 2006; Giumbelli, 2008, p. 92).

\footnotetext{
${ }_{6}^{6}$ A união política entre católicos e evangélicos também se deu em torno de outros projetos de lei, destacadamente, os relacionados à rejeição do aborto e da eutanásia (Duarte; Gomes; Menezes; Natividade, 2009).

${ }^{7}$ Católicos e evangélicos contam com frentes parlamentares próprias, compostas por deputados federais e senadores, embora os dirigentes da CNBB prefiram dialogar sem intermediários, publicamente ou nos bastidores, tanto com lideranças do governo federal, quanto do Congresso Nacional.

${ }^{8}$ Cabe lembrar que quando venceu as eleições em 2002, Lula fez aliança com o Partido Liberal (PL), que indicou seu vice, José Alencar e era então a legenda identificada com a Iurd.
} 
Outra questão fundamental em termos legais, não apenas em relação ao catolicismo, mas também quanto às demais religiões no Brasil, veio à tona em 2007, por ocasião da visita do papa Bento XVI, quando então foi divulgada a uma negociação entre o governo brasileiro e o Vaticano, por iniciativa deste. No ano seguinte, foi assinado em Roma, vindo a tramitar no Congresso Nacional em 2009 e sancionado no ano seguinte por Lula, o "Acordo entre a República Federativa do Brasil e a Santa Sé relativo ao Estatuto Jurídico da Igreja Católica no Brasil". O documento de vinte artigos trata de assuntos diversos: representação diplomática; personalidade jurídica e imunidade tributária para rendas e patrimônio de entidades católicas; situação trabalhista de sacerdotes e religiosos; concessão de visto para estrangeiros; integração de imóveis ao patrimônio histórico, artístico e cultural; assistência espiritual em instituições de internato; instituições de ensino; reconhecimento de títulos acadêmicos e ensino religioso em escolas públicas. ${ }^{9}$

Também chamado de concordata, esse acordo significou basicamente, por um lado, o reconhecimento jurídico do espaço próprio das entidades eclesiásticas no país; e por outro, a ampla permissão para as atividades católicas em outros domínios sociais, além da religião propriamente dita, envolvendo, sobremaneira: educação e assistência social. Como consequência dele houve mobilização política dos evangélicos, algo que levou o deputado federal George Hilton, membro da Iurd e do Partido Progressista (PP-MG) a apresentar um projeto de lei com as mesmas prerrogativas do acordo BrasilVaticano, porém voltado às demais instituições religiosas, sendo batizado de "Lei Geral das Religiões". Tal projeto de lei (PL 160) foi aprovado na Câmara dos Deputados em 26 de agosto de 2009, na mesma sessão em que, antes, a concordata católica também havia sido aceita, estando desde então aguardando tramitação no Congresso Nacional, pois embora com bastante força de pressão, os parlamentares evangélicos precisam lidar com robusta resistência política e institucional católica no país.

\section{Nuances entre religião e trabalho assistencial}

Tendo visto algumas das principais leis sobre organizações religiosas, passemos às questões assistenciais e depois às econômicas que elas envolvem. As chamadas obras sociais católicas, historicamente, têm considerável presença

\footnotetext{
${ }^{9}$ Vale dizer que a Lei de Diretrizes e Bases, de 1996, havia vetado o custeio do ensino religioso pelos cofres públicos, sendo que a Lei 9475, de 1997, revogou isso, embora proibisse "quaisquer formas de proselitismo". Paralelamente, o Conselho Nacional de Educação deliberou a transferência para as unidades federativas da regulamentação da disciplina (Junqueira, 2002; Giumbelli, 2004, p. 53).
} 
na sociedade brasileira. Nunca é demais lembrar que antes da instauração da República, a igreja era a grande provedora de educação, saúde e assistência social. E ainda nas primeiras décadas republicanas ela se manteve fundamental nessas áreas. Mas a instituição romana viu diminuir sua importância no Brasil, também nesse aspecto, uma vez que, por um lado, os governos gradativamente assumiram tais serviços públicos e, por outro, surgiram diferentes organizações religiosas e seculares, também executoras de trabalho assistencial (Quiroga, 2001). Mas esta igreja prossegue conduzindo muitas atividades desse tipo em suas paróquias, fundações, hospitais, associações e demais organismos, que atuam em diversas áreas: educação, saúde, abrigo, distribuição de alimentos, remédios, roupas, cobertores, materiais de higiene e de construção civil (Ceris, 2000).

Além do trabalho, principalmente de coleta e distribuição de alimentos e roupas, feito por movimentos tradicionais católicos. ${ }^{10} \mathrm{O}$ trabalho assistencial na igreja vem sendo feito por suas pastorais sociais. Entre elas se destacam as que auxiliam doentes e deficientes físicos, moradores de rua, presidiários, menores infratores, idosos e crianças carentes. A esse último segmento se dedica a maior e mais conhecida delas: Pastoral da Criança (Neumann, 2003).

Mas o organismo por excelência designado pela CNBB à assistência social é a Cáritas Brasileira. Com sua estrutura capilar, essa entidade dispõe de recursos arrecadados nas missas e provenientes de organizações de cooperação internacional para realizar seus programas de atendimento a famílias carentes, sobretudo aquelas residentes nas áreas mais pobres do país e as mais atingidas por calamidades, como estiagens, desabamentos e enchentes.

Em termos de práticas assistenciais, os evangélicos se caracterizaram pelas iniciativas de ajuda mútua, essencialmente no interior de suas próprias comunidades, sobretudo as que tinham também caráter étnico (Mendonça, 1984). As principais organizações não governamentais (ONGs) interdenominacionais formadas entre os protestantes históricos são: Diaconia, Coordenadoria Ecumênica de Serviço (Cese), Associação de Apoio à Criança e ao Adolescente - inicialmente Associação de Amparo ao Menor Carente (Amencar), Fundação Luterana de Diaconia (FLD), Visão Mundial e Rede Evangélica Nacional de Ação Social (Renas). Elas contam com recursos oriundos de outras organizações ecumênicas internacionais, bem como doações individuais e corporativas (Burity, 2006; Conrado, 2006; Scheliga, 2010).

\footnotetext{
${ }^{10}$ Damas da Caridade, Cruzada Eucarística, Filhas de Maria, Apostolado da Oração e, principalmente, Sociedade São Vicente de Paulo - SSVP (Novaes, 1998).
} 
De outro lado, no amplo espectro cristão, o espiritismo ganhou legitimidade e se difundiu na sociedade brasileira, em parte, devido ao significativo trabalho assistencial, chamado de "caridade material" (Simões, 2015). Basicamente ele envolve distribuição de alimentos e roupas, embora em muitos desses núcleos religiosos tal trabalho tenha se desenvolvido e diversificado, sobretudo em termos de atendimento a crianças carentes e deficientes físicos e mentais. Nesses casos, os centros espíritas deram lugar às chamadas casas assistenciais, contando cada qual com: estrutura física própria e independente, corpo profissional e especializado, bem como um conjunto de colaboradores voluntários individuais e parceiros corporativos (Giumbelli, 1995; Camurça, 2001). As principais entidades desse tipo são as paulistanas: Casas André Luiz; a soteropolitana Mansão do Caminho e o carioca Lar Fabiano de Cristo, tendo esta entidade diversas unidades espalhadas em trinta grandes cidades brasileiras (Souza e Simões, 2017).

A partir do trabalho caritativo de católicos, evangélicos e espíritas surgiram de fato muitas entidades assistenciais (Simões, 2003). Algumas delas vieram a se desligar organicamente de suas instituições religiosas, autonomizando-se por completo. É notória a proximidade do universo secular com o religioso, explícito em organizações de saúde pública e assistência social. Várias entidades desse tipo têm em sua designação termos cristãos e outras tantas são de conhecida origem religiosa (Landim, 1998). Há algumas ONGs católicas e também ecumênicas com predominância protestante, que são envolvidas em atividades de parceria com órgãos públicos e privados, lidam bastante bem com o princípio empresarial da responsabilidade social e participam de redes de colaboração mútua. Parte dessas organizações busca harmonizar as ideias de empreendedorismo e prosperidade dos adeptos religiosos com as atividades assistenciais por elas diretamente realizadas ou então apoiadas (Burity, 2003, Novaes, 2007; Scheliga, 2001; Conrado, 2006; Rosas, 2012).

As organizações religiosas compõem o amplo universo de entidades sem fins lucrativos, próprias do chamado terceiro setor, algo que tem como traço fundamental a mescla de trabalho voluntário e atividade profissional remunerada (Landim, 1993 e 1998; Fernandes, 1994; Novaes, 1995). Em 1999, a Lei no 9.790 criou a figura jurídica da Organização da Sociedade Civil de Interesse Público (Oscip), ${ }^{11}$ que estabelece critérios para que uma entidade seja reconhecida como idônea e apta para prestar serviços em pareceria com

\footnotetext{
${ }^{11}$ A primeira normatização formal no Brasil sobre entidades de "utilidade pública" ocorreu com a Lei $\mathrm{n}^{\mathrm{o}}$ 91, de 28 de agosto de 1935 (Giumbelli, 2002, p. 279).
} 
instâncias do poder público, sobremaneira de assistência social. Com diversos nomes - fundações, associações, centros etc. - elas recebem suporte direto de instâncias governamentais, empresas públicas e privadas, bem como de agências de cooperação internacional.

Desde 2002, as organizações sem fins lucrativos, incluindo as religiosas, recebem recenseamento, sendo o último levantamento disponível referente ao período de 2006 a 2010 (IBGE e Ipea, 2012). Além de religião, esse seguimento abrange as áreas: assistência social, saúde, habitação, cultura e recreação, educação e pesquisa, associações patronais e profissionais, meio ambiente e proteção animal, desenvolvimento e defesa de direitos. Somam mais de 290 mil entidades diferentes, sendo que as organizações religiosas perfazem 82,9 mil $(28,5 \%)$ do total. ${ }^{12}$ No entanto, a abrangência da religião nesse segmento é de fato maior e ainda desconhecida precisamente, dado que entidades assistenciais e educacionais, entre outras, têm origem religiosa, mas não são tipificadas como tal.

O recenseamento mostrou que as organizações religiosas são destacadamente as mais antigas, representando $39,5 \%$ das que foram criadas até 1980. Elas estão em segundo lugar entre as mais novas, com $27 \%$ do total, ficando atrás daquelas de defesa de direitos, que somam 30,6\%. No período entre 2006 e 2010 , as organizações religiosas foram as que tiveram maior crescimento entre todas as entidades recenseadas, com 11,2 mil unidades $(47,8 \%)$ das 23,4 mil que haviam sido formadas (IBGE e Ipea, 2010, p. 33). Tal como os dados demográficos sobre filiação religiosa, sabemos que a grande maioria delas é cristã.

No universo das atividades assistenciais há uma significativa diferença entre dois agrupamentos religiosos. Grosso modo, estão de um lado os católicos, espíritas, protestantes históricos e uma parte dos pentecostais tradicionais; e do outro, os neopentecostais e a outra parte dos pentecostais tradicionais. A diferença básica entre esses dois conjuntos é o tipo de envolvimento com a política partidária. Enquanto no primeiro ele é contido ou ausente, no segundo é algo bastante evidente (Souza, 2013). O caráter instrumental se dá também quanto ao objetivo de melhorar a imagem social das igrejas responsáveis por tais atividades, sedo um relevante exemplo o caso da Iurd (Giumbelli, 2002, p. 350-351).

\footnotetext{
${ }^{12}$ Estas abarcam: ordens religiosas e templos, entre outras, com pessoa jurídica própria. As demais instituições com origem religiosa que realizam outras atividades (hospitais, escolas, creches, por exemplo), são classificadas conforme sua atividade-fim.
} 


\section{Movimentação financeira e questões tributárias}

Constitucionalmente, como visto, as organizações religiosas têm assegurado o direito de reconhecimento da sua atuação pelo estado. Desde 1890, a Igreja Católica e, por conseguinte, as demais instituições religiosas dependem exclusivamente da contribuição financeira de seus próprios adeptos para se manter. O inciso VI do artigo 150 da Constituição de 1988 pró́be cobrança de impostos de "templos de qualquer culto", veto que, conforme o parágrafo $4^{\circ}$, abrange "o patrimônio, a renda e os serviços relacionados com as finalidades essenciais" das organizações religiosas. Tais finalidades envolvem funcionamento de templos, cultos, assistência religiosa, atividades filantrópicas e de formação teológica ou doutrinária (Tepedino, 1993).

A isenção de tributos federais, estaduais e municipais é, em termos materiais, a grande vantagem que uma organização religiosa tem. Conforme o inciso do artigo já citado da atual constituição brasileira, templos de qualquer culto são imunes a impostos sobre o patrimônio, a renda e os serviços ligados às suas finalidades essenciais. ${ }^{13}$ Além do Imposto de Renda (IR), os bens e as atividades ligadas às finalidades das organizações religiosas são isentos dos impostos: de Operação Financeira (IOF), Predial e Territorial Urbano (IPTU), sobre a Propriedade Territorial Rural (ITR), sobre Veículos Automotivos (IPVA) e sobre Serviços (ISS). Quanto ao tributo sobre Circulação de Mercadorias e Serviços (ICMS), grande parte das unidades federativas não o cobra em relação às contas de água, luz, gás e telefone de templos formalmente instituídos. Lideranças religiosas, sobretudo evangélicas, vêm fazendo tal reivindicação junto a candidatos a governos estaduais em troca de apoio eleitoral.

Para ter reconhecimento legal uma organização religiosa não precisa de nenhum requisito doutrinário, tampouco de um número mínimo de adeptos, bastando registrar ata de assembleia de fundação. Tal entidade pode ser formalmente constituída no prazo médio de uma semana, mediante gastos em cartório e junto à Receita Federal que somam menos de um salário mínimo nacional. Tomadas tais providências, seus fundadores passam a dispor de registro no Cadastro Nacional de Pessoa Jurídica (CNPJ), o que lhes permite movimentação bancária, inclusive aplicações financeiras, também isentas de tributação. Eis o caminho para a isenção fiscal, assegurado constitucionalmente.

\footnotetext{
${ }^{13}$ Sindicatos e partidos também gozam de isenção tributária, garantida constitucionalmente.
} 
Tal como as associações civis laicas, as organizações religiosas são legalmente proibidas de distribuir patrimônio ou renda a seus controladores. Mas nada impede que seus dirigentes, que são ministros religiosos ou sacerdotes, recebam proventos, algo que na prática é uma regra. Embora o empregado seja alguém que se enquadra no artigo 3 o da Consolidação das Leis de Trabalho (CLT), os ministros religiosos são tratados legalmente de modo diferente, compreendidos como contribuintes individuais à Previdência Social, conforme o dispositivo 9o, V, "c" do Decreto 3.048, de 1999. São, portanto, considerados autônomos, de acordo com a Lei 6.696, de 1979.

No meio jurídico, o trabalho religioso não é entendido como algo que constitui vínculo empregatício, dado que sua essência é a prestação de auxílio espiritual e assistência à comunidade de fiéis, divulgando a doutrina professada. Formalmente, não há vínculo de emprego entre os religiosos com dedicação exclusiva e suas respectivas instituições, embora haja esparsas contestações judiciais. O respaldo é o modelo jurídico impresso na nossa Lei 9.608, de 1998, que trata do trabalho voluntário. Entretanto, já ocorreram processos trabalhistas envolvendo religiosos profissionalizados e suas respectivas instituições. Também devido a isso, o Vaticano firmou o acordo com o estado brasileiro, que, entre outras coisas, isenta a instituição romana de processos trabalhistas por parte de clérigos, freiras e também leigos que prestam serviços remunerados como agentes de pastoral (Giumbelli, 2011).

Vale lembrar que os ministros religiosos gozam também de outros privilégios, como a isenção do serviço militar obrigatório, conforme o artigo 143 da atual constituição e direito à prisão especial, de acordo com o artigo 295 do Código de Processo Penal. Ainda em termos de permissão legal para atividades religiosas, no caso das chamadas religiões amazônicas: Santo Daime, União do Vegetal e Barquinha, há também autorização por parte do Ministério da Justiça para cultivar, transportar e ingerir os vegetais usados para a preparação do chá ritual e alucinógeno ayahuasca, algo proibido para quem não frequenta tais cultos.

A relativa facilidade de constituir uma organização religiosa e as vantagens materiais com as quais seus fundadores contam são fatores considerados relevantes na explicação da proliferação delas, sobremaneira as igrejas pentecostais (Aubrée, 1985). Os censos demográficos vêm registrando cada vez mais denominações diferentes e concorrentes no campo religioso brasileiro (Mariano, 2001; Mariz e Gracino Jr., 2013). As organizações religiosas contam com as contribuições financeiras de seus adeptos, feitas na forma de doações esporádicas, dízimos, correntes e campanhas com vários nomes e formatos. 
A Lei de Acesso à Informação ${ }^{14}$ permitiu que o jornal Folha de $S$. Paulo mostrasse em 27 de janeiro de 2013 algo contundente da economia das organizações religiosas. Trata-se do crescimento e da definição das origens dos recursos movimentados por elas. A arrecadação financeira anual delas cresceu de 18,4 bilhões em 2006 para 20,6 bilhões de reais em 2011 (aumento de 11,9\%). Desse valor, 3,47 bilhões (17\%) provinha de dízimos, enquanto 10,8 bilhões (52,4\%) vinham de doações aleatórias dos fiéis. A venda de bens e serviços era responsável por 3 bilhões (14,5\%) e os rendimentos com ações e aplicações financeiras geraram 460 milhões de reais. Pela primeira vez, havia acesso ao volume financeiro movimentado pelas organizações religiosas formalmente instituídas e que, portanto, precisam declarar anualmente a quantidade e a origem de seus recursos à Receita Federal. Isso porque elas passaram a preencher anualmente a Declaração de Informações Econômico-Fiscais da Pessoa Jurídica (DIPJ), que reúne dados sobre os valores arrecadados. O órgão governamental, por sua vez, mantém sob sigilo as informações das entidades declarantes, algo que inviabiliza divulgar os números de cada uma delas separadamente. Os recursos arrecadados são apresentados à Receita pelas instituições religiosas identificadas como matrizes. Cada uma tem seu próprio CNPJ e parte delas conta também com unidades filiais. Portanto, embora de modo limitado, existe sim algum controle público sobre o montante arrecadado pelas organizações religiosas.

\section{Organizações cristãs e atividades lucrativas}

Parte das instituições religiosas do escopo cristão têm envolvimento com atividades econômicas que são, na prática, lucrativas, com destaque para aquelas do setor de comunicação social, sobremaneira a mídia eletrônica. A Igreja Católica atua nessa área com suas emissoras ligadas a congregações, associações e dioceses, sendo algumas delas bastante associadas a clérigos e leigos fundadores, identificados com a Renovação Carismática, com destaque para as televisivas: Rede Vida, Canção Nova e TV Século 21 (Souza, 2007; Carranza, 2011; Placeres, 2015). Outro setor econômico em que os católicos são bastante atuantes é o turismo, com seus polos de peregrinação e todo aparato que os envolve, inclusive agências de viagem especializadas. Entidades católicas de marketing vêm se organizando no Brasil e promovendo feiras e demais atividades, até em âmbito internacional. Entre elas sobressaem o Instituto Brasileiro de Marketing Católico (IBMC) e a Promocat, empresa

${ }^{14}$ Lei número é 12.527 e foi sancionada em 2011, obriga órgãos públicos federais, estaduais e municipais a fornecerem informações sobre suas atividades a qualquer pessoa que solicitar os dados. 
promotora da Expocatólica, uma grande feira anual de produtos e serviços, ocorrida, às vezes, junto com outros eventos maiores, como foi o caso da $28^{\text {a }}$ Jornada Mundial da Juventude, no Rio de Janeiro, ocorrida em 2013 (Souza, Placeres e Moreno, 2014).

Porém não são os pentecostais católicos, mas sim os evangélicos aqueles que mais chamam atenção em termos de propriedade e gestão de empreendimentos econômicos. Sua relevância se deve ao volume e ao tamanho de seus negócios, bem como às controvérsias e implicações políticas. Especificamente, as denominações neopentecostais ${ }^{15}$ vez ou outra provocam o debate a respeito da ligação entre religião e atividades econômicas, destacadas pelas cifras movimentadas. Tendo como cerne a Teologia da Prosperidade, trata-se de uma vertente religiosa bastante adaptada ao modo como a sociedade contemporânea se organiza, com base na concorrência, não só econômica e política, mas também religiosa. As igrejas neopentecostais efetivamente se destacam em termos de atividades seculares e mercantis, sobretudo a Iurd, atuante em diversos ramos de negócios, incluindo o televisivo, principalmente através da Rede Record, comprada pelo fundador e líder iurdiano Edir Macedo em 1990 por 45 milhões de dólares (Mariano, 2003b; Souza, 2011).

De fato, a Teologia da Prosperidade cumpre um papel relevante no desenvolvimento da convicção dos neopentecostais de que o vínculo entre atividade religiosa e obtenção de lucro constitui algo, mais que natural, desejável e sistematicamente buscado. A propalada necessidade de expansão do televangelismo e seus altos custos dão suporte aos insistentes pedidos de contribuição financeira. O êxito econômico da Iurd tem sido referência para as demais denominações dessa vertente, a despeito das controvérsias e acusações judiciais já recaídas sobre ela. Feições empresariais e volume de recursos movimentos pela Iurd suscitaram o debate acerca de uma regulação maior das organizações religiosas, que, embora legalmente isentas de tributos, estão associadas por meio de seus líderes a algumas empresas, sendo o maior exemplo a relação dessa denominação com a Rede Record de Televisão (Pierucci, 1996, p. 275-285; Mariano, 2003a, p. 118-120; Lobato, 2005, p. 192-203).

\section{Considerações finais}

Para maior clareza dos contornos aqui delineados sobre as organizações cristãs, comecemos pela tipificação delas. O termo "organizações religiosas",

\footnotetext{
${ }^{15}$ Além da Iurd, são essas as principais igrejas: Internacional da Graça de Deus e Mundial do Poder de Deus, sendo seus fundadores e líderes, respectivamente: Romildo Soares e Valdemiro Santiago, ex-lideranças iurdianas.
} 
cunhado legalmente em 2003, diz respeito a um universo bastante amplo de entidades com atuação em várias frentes. Conforme os dados do censo das fundações e associações sem fins lucrativos, as organizações religiosas, em grande maioria cristãs, ${ }^{16}$ abrangem um número que na verdade é desconhecido, sendo algo maior que 82 mil unidades ( $28 \%$ do total), pois há muitas entidades com origem e identidade religiosas, embora recenseadas nas categorias de educação, saúde e assistência social. Há, portanto, certa promiscuidade na tipificação, camuflando a presença religiosa no que se entende por terceiro setor. Muitas organizações religiosas contam com títulos de utilidade pública e são, portanto, reconhecidas como entidades filantrópicas. Isso lhes autoriza a pleitear recursos de órgãos governamentais na condição de instituições educativas, sanitárias e assistenciais, gozando do princípio constitucional da "colaboração de interesse público".

Por outro lado, a isenção fiscal, legalmente assegurada, sobre patrimônios, rendas e serviços associados com fins religiosos não deixa de ter caráter controvertido na medida em que atividades religiosas propriamente ditas - essencialmente os cultos - por vezes, subsidiam práticas econômicas lucrativas. É mais uma vez elucidativo o caso da Iurd como instituição que cumpre papel de grande cliente da Rede Record. Há uma "zona cinzenta", encobrindo a aplicação efetiva dos recursos oriundos de dízimos e demais formas de doação financeira da parte de fiéis, a despeito da Lei de Acesso à Informação. Vale lembrar que é facultativa a prestação de contas dos dirigentes institucionais aos doadores. Sabe-se apenas que tais recursos, como um todo, vão bastante além de apenas garantir funcionamento de templos e atividades assistenciais, embora estas também cresçam, se diversificam prossigam sendo divulgadas para promoção institucional das respectivas igrejas.

Como visto, há uma profusão de empreendimentos econômicos com identidades: católica e evangélica, abrangendo diversas atividades. Aqueles que mais geram lucro se concentram na área de comunicação social, assumindo as formas de: editoras, gravadoras, produtoras audiovisuais, distribuidoras, emissoras televisivas e radiofônicas. Às vezes, os líderes religiosos compram emissoras já bem estruturadas que prosseguem suas atividades voltadas para um público bem mais amplo do que o segmento estritamente religioso, conforme os interesses econômicos de seus proprietários.

Dado que os principais empreendimentos econômicos conduzidos por lideranças e organizações religiosas são do campo midiático, cabem aqui algumas observações específicas. O Código Brasileiro de Tele-

\footnotetext{
${ }^{16}$ Entre as religiosas, as cristãs não são apenas maioria, mas também as mais institucionalizadas.
} 
comunicações (CBT), instituído em 1962, foi o primeiro e permanece o único marco regulatório do setor, sendo considerado já bastante defasado. A extinção do Conselho Nacional de Comunicação, em 2007, foi vista por alguns analistas também como um fator relevante em termos de desregulação das mídias eletrônicas no Brasil, sendo que parte significativa delas está nas mãos de líderes religiosos, com destaque para Edir Macedo. A despeito das polêmicas, a Iurd leva adiante suas atividades econômicas como uma grande organização religiosa com importantes traços mercantis, dotada de várias estratégias e técnicas de arrecadação financeira. Por outro lado, ela também realiza a articulação de tal êxito econômico com a diversificação de suas atividades assistenciais (Machado, 2003; Scheliga, 2010; Rosas, 2012).

As organizações religiosas utilizam os recursos que arrecadam com dízimos e doações para se reproduzirem e custearem parte das atividades assistenciais que realizam. Usam também para adquirir e ampliar seus instrumentos de comunicação, sobretudo as emissoras de rádio e televisão. Além desses empreendimentos, há outros e de diferentes tipos cuja propriedade é também de líderes religiosos. Em verdade, não se sabe efetivamente quanto dos recursos oriundos de doações acaba por ser revertido para atividades econômicas e aplicações financeiras ligadas a dirigentes religiosos. Embora atividades assistenciais se beneficiem efetivamente de tal arrecadação, o fato é que temos ainda uma questão controversa que, vez ou outra, reaparece no debate sobre a liberdade religiosa e organizacional.

\section{Referências}

AUBRÉE, Marion. L'expansion su pentecôtisme au Brésil. Braise - Revue Trimestrielle d'Information et Culture Brésilienne, v. 2, p. 37-43, 1985.

BARBOSA, Manoel. A igreja no Brasil. Rio de Janeiro: A noite, 1945.

BEOZZO, José Oscar. Religião e estado na história do Brasil. Veredas, v. 1, p. 107-124, 2000 .

BURITY, Joanildo. Religião e redes nas políticas sociais: legitimando a participação das organizações religiosas. Estudos da Religião. v. 27, n. 25, p. 12-47, 2003.

BURITY, Joanildo. Redes, parcerias e participação religiosa nas politicas sociais no Brasil. Recife: Fundação Joaquim Nabuco, 2006.

CAMURÇA, Marcelo. (2001). Fora da caridade não há religião: breve história da competição religiosa entre catolicismo e espiritismo kardecista e de suas obras sociais na cidade de Juiz de Fora: 1900-1960. Lócus, v. 7, n. 1, 2001, p. 131-154.

CARRANZA, Brenda. Catolicismo midiático. Aparecida: Idéias \& Letras, 2011.

CERIS. Obras sociais da Igreja Católica: atividades das instituições socioeducativas e das paróquias. São Paulo: Loyola, 2000. 
CONRADO, Flávio César. Religião e cultura cívica: um estudo sobre modalidades, contradições e complementaridades presentes nas ações sociais evangélicas no Brasil. Rio de Janeiro, 2006. Tese de doutorado em Antropologia Social, Universidade Federal do Rio de Janeiro.

DELLA CAVA, Ralph. Igreja e estado no Brasil do século 20: sete monografias recentes sobre o catolicismo brasileiro. Estudos Cebrap, n. 12, p. 5-52, 1975.

DUARTE, Luiz Fernando Dias; GOMES, Edlaine de Campos; MENEZES, Rachel Aisengart; NATIVIDADE, Marcelo (orgs.). Valores religiosos e legislação no Brasil: a tramitação de projetos de lei sobre temas morais controversos. Rio de Janeiro: Faperj, 2009.

FERNANDES, Rubem César. Privado, porém público: o terceiro setor na América Latina. Rio de Janeiro: Relume-Dumará, 1994.

GIUMBELLI, Emerson. Em nome da caridade: assistência social e religião nas instituições espíritas. Rio de Janeiro: Iser, 1995.

GIUMBELLI, Emerson. O fim da religião: dilemas da liberdade religiosa no Brasil e na França. São Paulo: Attar, 2002.

GIUMBELLI, Emerson. Religião, estado, modernidade: notas a propósito de fatos provisórios. Estudos Avançados, v. 18, n. 52, p. 47-62, $2004<10.1590 / \mathrm{S} 0103-$ 40142004000300005>.

GIUMBELLI, Emerson. A presença do religioso no espaço público: modalidades no Brasil. Religião e Sociedade, v. 28, n. 2, p. 80-101, $2008<10.1590 / \mathrm{S} 0100-$ $85872008000200005>$.

GIUMBELLI, Emerson. O acordo Brasil-Santa Sé e as relações entre estado, sociedade e religião. Porto Alegre. Ciencias Sociales y Religión, v. 13: n. 14, p. 119-143, 2011.

IBGE e Ipea. As fundações privadas e associações sem fins lucrativos no Brasil. Rio de Janeiro: IBGE, 2012.

JUNQUEIRA, Sérgio Rogério Azevedo. O processo de escolarização do ensino religioso no Brasil. Petrópolis, Vozes, 2002.

LANDIM, Leilah. Para além do mercado e do estado? Filantropia e cidadania no Brasil. Rio de Janeiro: Iser, 1993.

ANDIM, Leilah. Ações em sociedade: militância, caridade, assistência etc. Rio de Janeiro: Nau, 1998.

LOBATO, Elvira. Instinto de repórter. São Paulo: Publifolha, 2005.

MACHADO, Maria das Dores Campos. Igreja Universal: uma organização providência. In: Ari Pedro Oro; André Corten; Jean Pierre. Donzon (orgs.). Igreja Universal do Reino de Deus: os novos conquistadores da fé. São Paulo: Paulinas, 2003. p. 303-320.

MARIANO, Ricardo. Análise sociológica do crescimento pentecostal no Brasil. São Paulo, 2001. Tese de doutorado em Sociologia, Faculdade de Filosofia, Letras e Ciências Humanas, Universidade de São Paulo.

MARIANO, Ricardo. Efeitos da secularização do estado, do pluralismo e do mercado religioso sobre as igrejas pentecostais. Civitas, v. 3, n. 1, p. 111-125, 2003 a. 
MARIANO, Ricardo. O reino de prosperidade da Igreja Universal. In: Ari Pedro Oro; A. Corten; Jean Pierre Dozon (orgs.). Igreja Universal do Reino de Deus: os novos conquistadores da fé. São Paulo: Paulinas, 2003b. p. 237-258.

MARIANO, Ricardo. Secularização na Argentina, no Brasil e no Uruguai: suas lutas no passado e no presente. In: Ari Pedro Oro (org.). Religião e política no Cone Sul: Argentina, Brasil e Uruguai. São Paulo: Attar, 2006. p. 223-252.

MARIZ, Loreto Cecília; GRACINO JR., Paulo. As igrejas pentecostais no Censo de 2010. In: Faustino Teixeira; Renata Menezes (orgs.). Religióes em movimento: o censo de 2010. Petrópolis, Vozes, 2013. p. 161-176.

MENDONÇA, Antônio Gouvêa. O celeste porvir: a inserção do protestantismo no Brasil. São Paulo: Paulinas, 1984.

MONTERO, Paula. Controvérsias religiosas e esfera pública: repensando as religiões como discurso. Religião \& Sociedade, v. 32, n. 1, p. 167-183, $2012<10.1590 /$ S0100$85872012000100008>$.

NEUMANN, Zilda Arns. Lições da Pastoral da Criança: entrevista. Estudos Avançados, v. 17, n. 48, p. 63-75, $2003<10.1590 /$ S0103-40142003000200006>.

NOVAES, Regina (org.). Pobreza e trabalho voluntário: estudos sobre a ação social católica no Rio de Janeiro. Rio de Janeiro: Iser, 1995.

NOVAES, Regina. Juventude e ação social católica no Rio de Janeiro: resultados de pesquisa. In: Leilah Landim (org.). Ações em sociedade: militâncias, caridade, assistência, etc. Rio de Janeiro: Nau, 1998. p. 89-125.

NOVAES, Regina. Hábitos de doar: motivações pessoais e as múltiplas versões do “espírito da dádiva”. In: Márcia Brito; Maria Emília Melo (orgs.). Hábitos de doar e captar recursos no Brasil. São Paulo: Peirópolis, 2007. p. 15-56.

ORO, Ari Pedro. Religião e política no Brasil. In: Ari Pedro Oro (org.). Religião e política no Cone-Sul: Argentina, Brasil e Uruguai. São Paulo: Attar, 2006. p. 75-156.

ORO, Ari Pedro; CORTEN, André; DOZON, Jean Pierre (orgs.). Igreja Universal do Reino de Deus: os novos conquistadores da fé. São Paulo: Paulinas, 2003.

ORO, Ari Pedro; URETA, Marcela. Religião e política na América Latina: uma análise da legislação dos países. Horizontes Antropológicos. v. 13, n. 27, 2007, p. 281-310 $<10.1590 /$ S0104-71832007000100013>.

PIERUCCI, Antônio Flávio. Liberdade de cultos na sociedade de serviços. In: Antônio Flávio Pierucci; Reginaldo Prandi (orgs.). A realidade social das religiões no Brasil. São Paulo, Hucitec, 1996.

PINHEIRO, Douglas Antônio Rocha. Direito, estado e religião: a constituinte de 1987-1988 e a reconstrução da identidade religiosa do sujeito constitucional brasileiro. Brasília, 2008. Dissertação de mestrado em Direito, Universidade de Brasília.

PLACERES, Giulliano. O empreendedorismo econômico-televisivo da Rede Vida. São Carlos, 2015, Dissertação de mestrado em Sociologia, Universidade Federal de São Carlos.

QUIROGA, Ana Amaria. Caridade, filantropia e justiça e os modelos de ação social. Praia Vermelha, v. 5, p. 40-59, 2001. 
RANQUETAT JR., Cesar Alberto. A invocação do nome de Deus nas constituições federais brasileiras: religião, política e laicidade. Cultura y Religión. v. 7, n. 2, p. 86-101, 2013.

ROMANO, Roberto. Brasil: igreja contra estado. São Paulo: Kairós, 1979.

ROSAS, Nina. As ações sociais da Igreja Universal: recrutamento e empreendedorismo no agente da comunidade de Belo Horizonte. Ciencias Sociales y Religión. v. 14, n. 17, p. 27-51, 2012.

SCAMPINI, José. A liberdade religiosa nas constituições brasileiras. Petrópolis: Vozes, 1978.

SCHELIGA, Eva Lenita. Educando sentido, orientando uma práxis: etnografia das práticas assistenciais de evangélicos brasileiros. Tese (Doutorado em Antropologia Social) - Universidade de São Paulo, São Paulo, 2010.

SIMÕES, Pedro. Religião, espiritualidade e assistência social. Revista Brasileira de Informação em Ciências Sociais, n. 56, p. 17-32, 2003.

SIMÕES, Pedro. Dá-me de comer: a assistência social espírita. São Paulo, CCDPELHIPE, 2015.

SOUZA, André Ricardo. Igreja Católica e mercados: a ambivalência entre a solidariedade e a competição. Religião \& Sociedade, v. 27, n. 1, p. 156-174. $2007<10.1590 /$ S0100-85872007000100008>.

SOUZA, André Ricardo. O empreendedorismo neopentecostal no Brasil. Ciencias Sociales y Religión, v. 13, n. 15, p. 13-34, 2011.

SOUZA, André Ricardo. Traços e embaraços do trabalho assistencial cristão. Estudos de Sociologia, v. 18, n. 34, 2013.

SOUZA, André Ricardo de; PLACERES, Giulliano; MORENO, Pedro Augusto. A Jornada Mundial da Juventude como um produto católico de turismo e televisão. Plura - Revista de Estudos de Religião, v. 5, p. 51-65, 2014.

SOUZA, André Ricardo de; SIMÕES, Pedro. Desafios do trabalho assistencial espírita: dois modelos de atuação. Rever, v. 17, n. 1, p. 123-145, $2017<10.23925 /$ 1677-1222.2017vol17i1a7>.

TEPEDINO, Gustavo. Aspectos polêmicos do tratamento fiscal conferido aos templos e às entidades de fins religiosos. Revista da Procuradoria Geral da República, n. 5, p. 57-79, 1993.

Recebido em: 6 jul. 2016

Aprovado em: 18 dez. 2017

Autor correspondente:

André Ricardo de Souza

Rua Veríssimo da Mota, 9

02562-030 São Paulo, SP, Brasil 